\title{
Antiretroviral treatment associated hyperglycemia and dyslipidemia among HIV infected patients at Burayu Health Center, Addis Ababa, Ethiopia: a cross-sectional comparative study
}

Molla Abebe ${ }^{1 *}$, Samuel Kinde ${ }^{2}$, Getachew Belay ${ }^{3}$, Atsbeha Gebreegziabxier ${ }^{3}$, Feyissa Challa ${ }^{3}$, Tefera Gebeyehu ${ }^{3}$, Paulos Nigussie ${ }^{3}$ and Belete Tegbaru ${ }^{3}$

\begin{abstract}
Background: The effects of highly active antiretroviral therapy (HAART) on glucose and lipid metabolism among sub-Saharan Africans, for whom access to antiretroviral therapy is expanding, remain largely unknown. Therefore, the aim of this study was to assess antiretroviral treatment associated hyperglycemia and dyslipidemia among HIV infected patients at Burayu health center, Addis Ababa, Ethiopia.

Methods: A cross-sectional comparative study was conducted among HIV infected adults at Burayu Health Center, Addis Ababa, Ethiopia from September, 2011 to May, 2012. Equal number of HAART naïve and HAART initiated patients ( $n=126$ each) were included in the study. Demographic data were collected using a well-structured questionnaire. Total cholesterol (TC), Triglyceride (TG), high density lipoprotein cholesterol (HDL-C), low density lipoprotein cholesterol (LDL-C) and glucose were determined. The data were analyzed using SPSS version 20 software.

Result: Of 252 study participants, $72.2 \%$ were females; mean age was 35.3 years; mean Body Mass Index (BMI) was 21.4 $\left(\mathrm{kg} / \mathrm{m}^{2}\right)$; mean time living with the virus was 20.6 months and 15.5\% were TB-HIV co-infected. The prevalence of hyperglycemia, increased LDL-C hypercholesterolemia, hypertriglyceridemia and decreased HDL-C were 7.9\%, 23\%, 42.1\%, 46.8\% and 50.8\% in HAART and 5.6\%, 7.1\%, 11.1\%, 31\% and 73\% in non-HAART groups, respectively. First line antiretrovirals were drugs containing 2 nucleoside backbones (from Zidovudine/Stavudine/Lamivudine/Tenofovir) with either Nevirapine or Efavirenz. There was statistically significant increase in serum lipid profile levels among HAART initiated patients than HAART naïve individuals ( $p=0.01$ for TG and $<0.001$ for others).

Conclusion: First-line HAART is associated with potentially atherogenic lipid profile levels in patients with HIV infection compared to untreated patients. This indicates glucose and lipid profile levels need to be monitored regularly in HIV infected patients taking antiretroviral treatment.
\end{abstract}

Keywords: HIV/AIDS, Dyslipidemia, Hyperglycemia, Antiretroviral therapy, Ethiopia

\footnotetext{
* Correspondence: mollish77@gmail.com

'Department of Clinical Chemistry, School of Biomedical and Laboratory Sciences, College of Medicine and Health Sciences, University of Gondar, Gondar, Ethiopia

Full list of author information is available at the end of the article
} 


\section{Background}

Highly active antiretroviral therapy (HAART) is the mainstay of treatment for those infected with HIV [1]. Since its introduction in 1996, mortality and morbidity rates in HIVinfected individuals in countries with widespread access to HAART have plummeted. The main effect of HAART is to suppress viral replication, allowing the individual's immune system to recover and protecting from the development of AIDS and death [2]. In recent years, provision of HAART to those in need has become an increasingly important and feasible global priority [3]. However, the prospect of maintaining patients on long term HAART may be restricted by a heterogeneous collection of unexpected metabolic abnormalities, including dysregulation of glucose metabolism, dyslipidemia, and/or lipodystrophy [4,5]. Use of HAART has been linked to hyperglycemia, dyslipidemia and increased risk of cardiovascular disease (CVD) in HIVinfected patients in industrialized countries. The effects of HAART on glucose and lipid metabolism among subSaharan Africans, for whom access to antiretroviral therapy is expanding, remain largely unknown [6]. This is specially a major gap that should be given high emphasis in a county like Ethiopia where increased use of HAART is higher since 2005. Therefore, the aim of this study was to assess antiretroviral treatment associated hyperglycemia and dyslipidemia among HIV infected patients at Burayu health center, Addis Ababa, Ethiopia.

\section{Methods}

\section{Study design, setting and period}

A cross-sectional comparative study was conducted at voluntary counseling and testing (VCT) center of Burayu Health Center in collaboration with Ethiopian Health and Nutrition Research Institute (EHNRI) from September, 2011 to May, 2012. Two groups of study participants with age $\geq 18$ years who were either on HAART for at least six months (HAART initiated group) and HAART naïve HIV patients (non-HAART groups) who visited the VCT center during the study period were included in the study. First-line HAART regimens used were nucleoside reverse transcriptase inhibitors (NRTIs) [lamivudine (3TC), zidovudine (AZT), stavudine (D4T) or Tenofovir (TDF)] and non-nucleoside reverse transcriptase inhibitors (NNRTIs) [nevirapine (NVP) or efavirenz (EFV)]. Patients with hyperglycemia or dyslipidemia at baseline (for HAART initiated patients) and pregnant women and nursing mother were excluded.

\section{Data collection}

Consecutive sampling technique was employed to include study participants. Two hundred fifty two (126 HAART initiated and 126 non-HAART) participants were enrolled. After having received a clear explanation of the objective, risk and confidentiality of the study, participants signed the informed consent and participated in the study. Demographic data regarding, age, gender, period with HIV infection, ART exposure in the previous six months and the ARV regimen were collected using questionnaire. Medical records were also used to confirm the information and baseline glucose and lipid profile levels. Height and weight were measured to calculate body mass index (BMI). Six to ten $\mathrm{ml}$ of blood sample was collected by venipuncture from 8-12 hours fasting individuals using vacuum tube (Becton Dickinson, SA) and serum was separated within one hour of blood collection. The serum levels of glucose, TC, HDL-C, LDL-C and TG were measured using COBAS INTEGRA 400 random access full automated auto analyzer at EHNRI, clinical chemistry laboratory. Glucose was determined by Hexokinase (HK) method, TG and total TC were evaluated with enzymatic colorimetric method and HDL-C and LDL-C were analyzed by homogenous enzymatic colorimetric method. CD4+ lymphocyte count was determined using flow cytometer (FACSCalibur, Becton Dickinson, CA, USA). Tuberculosis (TB) was diagnosed via microscopy from sputum sample and X-ray photography if smear negative TB encountered.

The cutoff points to categorize dyslipidemia was defined as TC $\geq 200 \mathrm{mg} / \mathrm{dl}$, HDL-c $<40 \mathrm{mg} / \mathrm{dl}$, LDL-c $\geq 130 \mathrm{mg} / \mathrm{dl}$, $\mathrm{TG} \geq 150 \mathrm{mg} / \mathrm{dl}$ and hyperglycemia as glucose $\geq 110 \mathrm{mg} / \mathrm{dl}$ and were based on the United States National Cholesterol Education Program, Adult Treatment Panel (NCEP-ATP) III guideline [7].

\section{Data analysis}

Data were entered and analyzed using Statistical Package for Social Sciences (SPSS) window version 20 (IBM Statistics, USA). Chi-square, student-t-test and logistic regression tests were used to see the association between sociodemographic characteristics, duration with HIV, BMI and HAART regimens with serum glucose and lipid profile levels. P-Value $<0.05$ was considered to be statistically significant at $95 \%$ confidence interval (CI).

\section{Ethical consideration}

The study was ethically cleared from the Departmental Research and Ethics Review Committee of Department of Medical Laboratory Sciences, College of Health Sciences, Addis Ababa University, Oromia Regional Health Bureau Ethical Review Committee, EHNRI Scientific and Ethical Review Committee and National Research Ethics committee of Ethiopia. VCT center counselors (nurses from the Health Center) who collected patient data were oriented and trained to keep data confidentiality. Patients received their results through clinicians for further diagnosis and treatment accordingly. 


\section{Results}

Socio demographic characteristics of study subjects

A total of $252 \mathrm{HIV}$ infected patients were enrolled in the study. Of these, 126 (50\%) were initiated HAART (HAART group) and 126 (50\%) were ART naive (nonHAART group). Majority of the study participants were females (182 (72.2\%)). Of those HAART groups, 86 (68.3\%) were females. In addition, among non-HAART groups, $96(76.2 \%)$ were females. The overall mean age was $35.3 \pm 10.2$ years (range: 18 to 75 years). The total time from the serological diagnosis of HIV infection was $20.6 \pm 17.3$ months (Mean \pm SD) and was longer in HAART group compared to non-HAART group (mean: $29.5 \pm 17.1$ versus $11.8 \pm 12.3$ months, $\mathrm{p}<0.0001)$. Thirty four (27\%) HAART groups and 25 (19.8\%) non-HAART groups had CD4+ cells $<200$ cells $/ \mathrm{mm}^{3}$. Of all the subjects, 39 (15.5\%) had TB-HIV co infection during the study period $[21(16.7 \%)$ of the HAART and 18 (14.3\%) non-HAART groups] (Table 1 ).

\section{Characteristics of serum fasting glucose and lipid profile levels}

Totally, 17 (6.7\%) individuals had abnormally high fasting serum glucose level. There was no significant difference in serum glucose level between HAART initiated and non-HAART groups $(\mathrm{P}=0.45)$. However, there was higher serum lipid profile levels among HAART groups than HAART naïve individuals ( $p=0.01$ for TG and $<0.001$ for others) (Table 2).

\section{Serum fasting glucose/lipid profile level and HAART}

Most of the HAART initiated patients $(43,34.1 \%)$ were on ART for 13-24 months followed by those for 25-41 months (42, 33.3\%). The rest 28 (22.2\%) and 13 (10.3\%) were on ART for 6-12 months and above 3.5 years, respectively. Duration of HAART was not significantly associated with serum glucose/lipid profile levels.

A total of 4 nucleoside reverse transcriptase inhibitors [Lamivudine (3TC), Zidovudine (AZT), Stavudine (D4T) and Tenofovir (TDF)] and 2 non-nucleoside reverse transcriptase inhibitors [Nevirapine (NVP) and Efavirenz (EFV) with 5 combinations (D4T-3TC-NVP, AZT-3TCEFV, D4T-3TC-EFV, AZT-3TC-NVP and TDF-3TCEFV] were used to treat patients. Nevirapine and EFV based combinations were used by almost equivalent number of individuals [65(51.6\%) versus 61(48.4\%), respectively]. In addition, D4T and AZT based ARVs were used by $47(37.3 \%)$ and 67 (53.2\%) individuals, respectively. AZT-3TC-NVP combinations of antiretrovirals were the most frequently used drugs among the HAART initiated study participants, [36 (28.6\%)] while TDF3TC-EFV combinations were relatively used by small number of patients, [12 (9.5\%)] (Figure 1). No significant difference observed in glucose/lipid profile derangements

\begin{tabular}{|c|c|c|c|}
\hline \multirow[t]{2}{*}{ Variable } & & $\begin{array}{l}\text { HAART initiated } \\
(n=126)\end{array}$ & $\begin{array}{l}\text { Non-HAART } \\
(n=126)\end{array}$ \\
\hline & & N (\%) & N (\%) \\
\hline \multirow[t]{2}{*}{ Gender } & Female & $86(68.3)$ & $96(76.2)$ \\
\hline & Male & $40(31.7)$ & $30(23.8)$ \\
\hline \multirow{5}{*}{$\begin{array}{l}\text { Age group } \\
\text { (years) }\end{array}$} & Mean \pm SD & $37.1(9.8)$ & $33.4(10.2)$ \\
\hline & $18-29$ & 25(19.8) & $51(40.5)^{* *}$ \\
\hline & $30-39$ & $61(48.4)$ & $49(38.9)$ \\
\hline & $40-49$ & $25(19.8)$ & $16(12.7)$ \\
\hline & $\geq 50$ & 15(11.9) & 10(7.9) \\
\hline \multirow[t]{5}{*}{ BMI } & Mean \pm SD & 21.9(3.2) & $20.8(2.8)$ \\
\hline & $<18.5$ & $9(7.1)$ & $24(19)^{*}$ \\
\hline & $18.5-24.9$ & $97(77)$ & $91(72.2)$ \\
\hline & $25-29.9$ & $17(13.5)$ & 10(7.9) \\
\hline & $\geq 30$ & $3(2.4)$ & $1(0.8)$ \\
\hline \multirow{4}{*}{$\begin{array}{l}\text { CD4+ cells } \\
\left.\text { (cells } / \mathrm{mm}^{3}\right)\end{array}$} & Mean \pm SD & $314.5 \pm 152.5$ & $413.6 \pm 246.2$ \\
\hline & $<200$ & $34(27)$ & $25(19.8)^{* *}$ \\
\hline & $200-400$ & $58(46)$ & $42(33.3)$ \\
\hline & $>400$ & $34(27)$ & $59(46.8)$ \\
\hline \multirow{6}{*}{$\begin{array}{l}\text { Duration of HIV } \\
\text { infection (month) }\end{array}$} & Mean \pm SD & $29.5(17)$ & $11.8(12.3)$ \\
\hline & $<6$ & $0(0)$ & $57(45.2)^{* * *}$ \\
\hline & $6-12$ & $22(17.5)$ & $21(16.7)$ \\
\hline & $13-24$ & $22(17.5)$ & $27(21.4)$ \\
\hline & $25-41$ & $59(46.8)$ & $19(15.1)$ \\
\hline & $\geq 42$ & 23(18.3) & $2(1.6)$ \\
\hline \multirow[t]{2}{*}{ TB Co-infection } & Present & $21(16.7)$ & 18(14.3) \\
\hline & $\begin{array}{l}\text { Not } \\
\text { present }\end{array}$ & 105(83.3) & 108(85.7) \\
\hline
\end{tabular}

$\mathrm{N}$, number; BMI, body mass index; HAART, highly active antiretroviral therapy; TB, tuberculosis; SD, standard deviation; ${ }^{*} \mathrm{p}$-value $=0.02 ;{ }^{* *} \mathrm{p}$-value $=0.004$; ***p-value $<0.0001$

between patients receiving AZT based combinations compared to those on D4T; and patients treated with EFV based combinations versus those treated with NVP (Table 3).

\section{Serum glucose/lipid profile levels and risk factors}

Using univariate analysis, there was no statistically significant association between serum glucose/lipid profile levels and gender. However, there were statistically significant association between TG and HAART initiation, TC and HAART initiation, HDL-C and HAART initiation, and LDL-C and HAART initiation ( $\mathrm{p}=0.01,<0.0001,<0.0001$ and 0.001 , respectively). Glucose was not affected by different variables except by CD4+cells ( $p=0.023$ ). Similarly, tuberculosis (TB) co-infection slightly affected serum LDL-C level only ( $\mathrm{p}=0.49)$ (Table 4). 
Table 2 Serum lipid profile and glucose levels of study population by HAART status at Burayu Health Center, Addis Ababa, Ethiopia, 2012

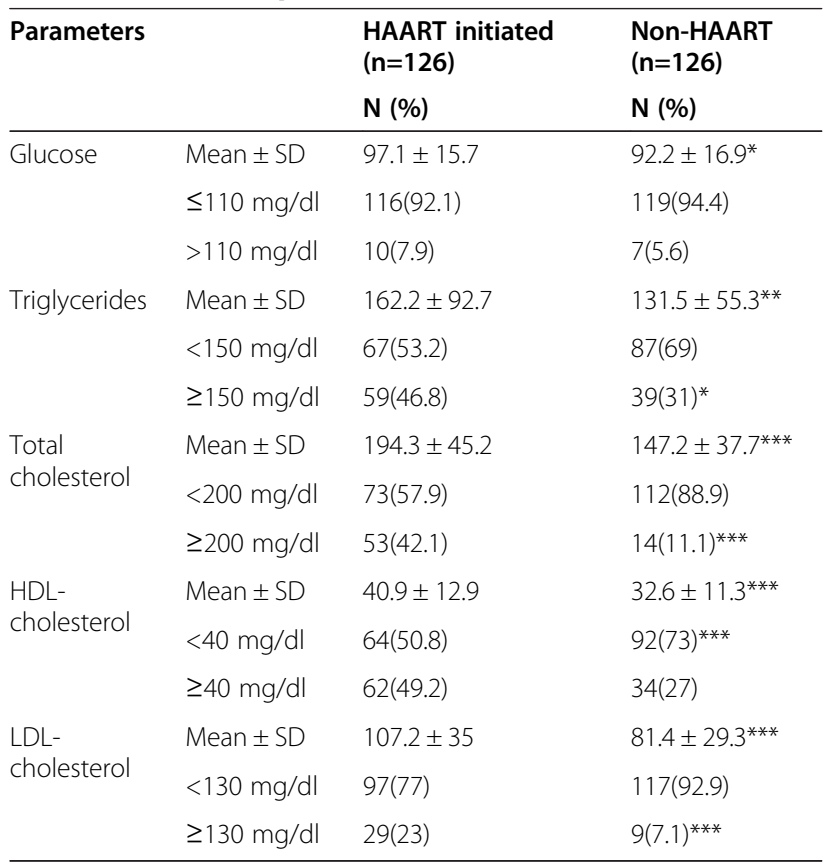

HAART, highly active antiretroviral therapy; $\mathrm{HDL}$, high-density lipoprotein; $\mathrm{LDL}$, low- density lipoprotein; SD, standard deviation; ${ }^{*} \mathrm{p}$-value $=0.01 ;{ }^{* *} \mathrm{p}$-value $=0.002$; *** p-value $<0.0001$.

Adjusting for potential confounding factors such as gender, age, BMI, CD4 + cells, duration with HIV, TB coinfection and HAART initiation, HAART initiation and BMI had an independent and positive association with raised serum $\mathrm{TC}$ level. In addition, HAART initiation was independently associated with serum HDL-C and LDL-C levels (Table 5).

\section{Discussion}

In this study, we tried to address how presence and absences of HAART affects glucose and lipid profile levels in HIV positive individuals.

Our results showed an increased prevalence of hyperglycemia, hypercholesterolemia and hypertriglyceridemia in patients receiving ARV drugs than non-HAART study participants. The prevalence of hyperglycemia (>110 mg/ dl), low density lipoprotein cholesterol (LDL-C) hypercholesterolemia $(\geq 130 \mathrm{mg} / \mathrm{dl})$, total cholesterol (TC) hypercholesterolemia ( $\geq 200 \mathrm{mg} / \mathrm{dl}$ ), hypertriglyceridemia $(\geq 150 \mathrm{mg} / \mathrm{dl})$ and high density lipoprotein cholesterol (HDL-C) hypocholesterolemia (<40 mg/dl) were $7.9 \%$, $23 \%, 42.1 \%, 46.8 \%$ and $50.8 \%$ in HAART initiated and $5.6 \%, 7.1 \%, 11.1 \%, 31 \%$ and $73 \%$ in non-HAART groups, respectively.

In this study, we found comparable percentage of HAART initiated individuals (7.9\%) and non- HAART group (5.6\%) who had an increased serum glucose level and HAART initiation was not associated ( $\mathrm{p}=0.45)$. However, HAART group showed higher mean glucose level than non-HAART group ( $\mathrm{p}=0.019$ ). In agreement to this finding, a study in Brazil observed elevated glucose levels in $6.8 \%(7 / 103)$ patients treated without PIs, $1.5 \%(2 / 134)$ patients receiving PIs and $0.9 \%(1 / 112)$ non-HAART individuals despite the small number cases limited their conclusions [8].

Among our study subjects, there was no association between serum glucose/lipid level and gender. However,

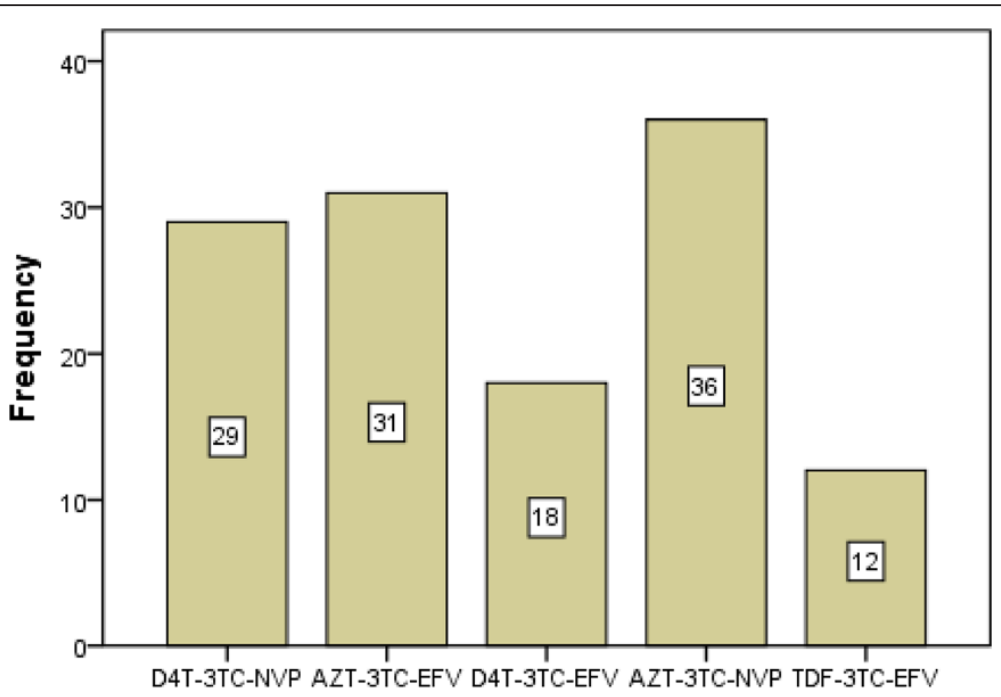

Type of HAART Used by HIV Patients

Figure 1 Frequency of different combinations of antiretroviral drugs used by HIV infected patients at Burayu Health Center, Addis Ababa, Ethiopia, 2012. 
Table 3 Serum glucose and lipid profile levels distribution among different combinations of HAART taken by study participants at Burayu Health Center, Addis Ababa, Ethiopia, 2012

\begin{tabular}{|c|c|c|c|c|}
\hline \multicolumn{2}{|c|}{ Glucose/lipid profile } & \multicolumn{2}{|c|}{$\begin{array}{l}\text { NVP versus EFV based } \\
\text { combination of ARVs }\end{array}$} & \multirow[t]{3}{*}{ P-value } \\
\hline & & NVP $(n=65)$ & $\operatorname{EFV}(n=61)$ & \\
\hline & & N (\%) & N (\%) & \\
\hline \multirow[t]{2}{*}{ Glucose } & $\leq 110$ & $60(92.3)$ & $56(91.8)$ & 0.917 \\
\hline & $>110$ & $5(7.7)$ & $5(8.2)$ & \\
\hline \multirow[t]{2}{*}{ Triglyceride } & $<150$ & $37(56.9)$ & $30(49.2)$ & 0.384 \\
\hline & $\geq 150$ & 28(43.1) & $31(50.8)$ & \\
\hline \multirow[t]{2}{*}{ Total cholesterol } & $<200$ & $37(56.9)$ & $36(59)$ & 0.812 \\
\hline & $\geq 200$ & 28(43.1) & $25(41)$ & \\
\hline \multirow[t]{2}{*}{ HDL-cholesterol } & $<40$ & $28(43.1)$ & $36(59)$ & 0.074 \\
\hline & $\geq 40$ & $37(56.9)$ & $25(41)$ & \\
\hline \multirow[t]{2}{*}{ LDL-cholesterol } & $<130$ & 48(73.8) & 49(80.3) & 0.388 \\
\hline & $\geq 130$ & $17(26.2)$ & 12(19.7) & \\
\hline \multirow{3}{*}{\multicolumn{2}{|c|}{ Glucose/lipid profile }} & \multicolumn{2}{|c|}{$\begin{array}{l}\text { D4T versus AZT based } \\
\text { combination of ARVs }\end{array}$} & P-value \\
\hline & & D4T $(n=47)$ & AZT $(n=67)$ & \\
\hline & & N (\%) & N (\%) & \\
\hline \multirow[t]{2}{*}{ Glucose } & $\leq 110$ & $40(85.1)$ & $64(95.5)$ & 0.053 \\
\hline & $>110$ & $7(14.9)$ & $3(4.5)$ & \\
\hline \multirow[t]{2}{*}{ Triglyceride } & $<130$ & $25(53.2)$ & $35(52.2)$ & 0.920 \\
\hline & $\geq 130$ & $22(46.8)$ & $32(47.8)$ & \\
\hline \multirow[t]{2}{*}{ Total cholesterol } & $<200$ & 28(59.6) & $39(58.2)$ & 0.884 \\
\hline & $\geq 200$ & 19(40.4) & 28(41.8) & \\
\hline \multirow[t]{2}{*}{ HDL-cholesterol } & $<40$ & $26(55.3)$ & $33(49.3)$ & 0.524 \\
\hline & $\geq 40$ & $21(44.7)$ & $34(50.7)$ & \\
\hline \multirow[t]{2}{*}{ LDL-cholesterol } & $<130$ & $37(78.7)$ & 53(79.1) & 0.961 \\
\hline & $\geq 130$ & 10(21.3) & 14(20.9) & \\
\hline
\end{tabular}

AZT, Zidovudine; d4T, stavudine; EFV, efavirenz; NVP, nevirapine; $p$, significance level.

according to a study from Thailand on 200 HAART treated patients for an average of 39.35 months, the prevalence of hyperlipidemia was higher in men than women despite no difference in blood glucose level between the two. Among those reported patients, 6.5\%, 10.5\%, 34.0\% and $35.5 \%$ developed increased LDL-C, diabetes mellitus, hypercholesterolemia and hypertriglyceridemia, respectively [9]. The discrepancy with our study may be due to our study participants were not gender matched between the two groups.

Increased serum lipid profile level was associated with HAART initiation ( $\mathrm{p}=0.01$ for TG and $<0.0001$ for others) in our study. Similar to our findings, a cross-sectional study from India showed significantly higher prevalence of dyslipidemia in the first line treatment groups [10]. Moreover, according to a study from the same country, at baseline and at 12 months, TC was $>200 \mathrm{mg} / \mathrm{dl}$ for $1 \%$ and $26 \%$ of patients; LDL-C level was $>130 \mathrm{mg} / \mathrm{dl}$ for $3 \%$ and 23\%; HDL-C level was $<40 \mathrm{mg} / \mathrm{dl}$ for $91 \%$ and $23 \%$ and blood glucose level was $>110 \mathrm{mg} / \mathrm{dl}$ for $14 \%$ and $13 \%$, respectively [11].

In Canada, among 745 ARV treated patients, 10\% and $16 \%$ showed increased TG and TC levels, respectively [12]. Unlike to the above and in agreement with ours a study from Cameroon showed the prevalence of $\mathrm{TC} \geq 200 \mathrm{mg} / \mathrm{dl}$ as $37.6 \%$ and $24.6 \%$, respectively in ART groups and ART naive groups $(\mathrm{p}=0.019)$. The equivalents for $\mathrm{LDL}-\mathrm{C} \geq 130$ $\mathrm{mg} / \mathrm{dl}$ were $46.4 \%$ and $21 \%(\mathrm{p} \leq 0.001)$ [13].

Inline to our finding, a long term analysis on plasma lipid concentration was performed in patients starting first-line antiretroviral therapy in Netherlands and showed concentrations of TC, LDL-C and TG continued to increase with slight decrease in HDL-C [14]. Similarly, a study from Cameroon showed TC, LDL-C and HDL-C levels increased significantly $(\mathrm{P}<0.05)$ but $\mathrm{TG}$ remained unaltered with first line ARV therapy for 3 months [15]. This might be due to short treatment period.

In our HAART initiated study participants, the mean serum HDL-C, LDL-C, TG and TC levels were 40.9, 107.2, 162.2 and $194.3 \mathrm{mg} / \mathrm{dl}$, respectively. The result of another 1 year follow up study in Italy showed elevated mean levels of serum HDL-C, $40.1 \mathrm{mg} / \mathrm{dl}$; LDL-C, $165.2 \mathrm{mg} / \mathrm{dl}$; TC, $258.7 \mathrm{mg} / \mathrm{dl}$ and TG, $306.4 \mathrm{mg} / \mathrm{dl}$ than ours. These mean differences might be probably due to population difference in Ethiopia and Italy. They found decreased HDL-C level 9.4\%, hypercholesterolemia 25\%, increased LDL-C level $26.7 \%$ and hypertriglyceridemia $38.2 \%$ [16] which was almost comparable with our results. Moreover, a 5 year cohort study in Switzerland found that non-HDL-C levels increased with increasing exposure to either PIs or NNRTI based therapy, HDL-C level increased and TG level decreased with increasing exposure to NNRTI based therapy; whereas TG levels increased with increasing exposure to PI-based therapy [17].

In logistic regression adjusted for age group, duration with HAART, BMI, CD4+ cell count, and TB-HIV coinfection, HAART initiation was significantly associated with serum TC, HDL-C and LDL-C levels. Similarly, a study conducted in Cameroon in 2011, in multivariable analysis adjusted for age, sex, BMI, CD4+ cell count and co-infection with tuberculosis, being on ART was significantly and positively associated with raised TC and LDL-C with adjusted odd ratios (95\% CI, p-value) ARTtreated versus ART-naïve was $1.82(1.06-1.12, \mathrm{p}=0.02)$ for $\mathrm{TC} \geq 200 \mathrm{mg} / \mathrm{dl}$ and $2.99(1.74-5.15), \mathrm{p}<0.0001)$ for LDL-C $\geq 130 \mathrm{mg} / \mathrm{dl}$ [13].

With a combination of at least three drugs including NRTI, NNRTI and PIs, HAART is currently used to control the replication of HIV and AIDS [8]. Even though, the national ART guideline for adolescents and 
Table 4 Association of glucose and lipid profile levels and other variables at Burayu Health Center, Addis Ababa, Ethiopia, 2012

\begin{tabular}{|c|c|c|c|c|c|}
\hline \multirow[t]{2}{*}{ Variables } & \multicolumn{5}{|c|}{ Glucose/lipid profile levels } \\
\hline & $\begin{array}{l}\text { Gluc >110 mg/dl } \\
\text { UOR }(95 \% \mathrm{Cl})\end{array}$ & $\begin{array}{l}\text { TG } \geq 150 \mathrm{mg} / \mathrm{dl} \\
\text { UOR }(95 \% \mathrm{Cl})\end{array}$ & $\begin{array}{l}\mathrm{TC} \geq 200 \mathrm{mg} / \mathrm{dl} \\
\text { UOR }(95 \% \mathrm{Cl})\end{array}$ & $\begin{array}{l}\mathrm{HDL}<40 \mathrm{mg} / \mathrm{dl} \\
\text { UOR }(95 \% \mathrm{Cl})\end{array}$ & $\begin{array}{l}\mathrm{LDL} \geq 130 \mathrm{mg} / \mathrm{dl} \\
\text { UOR }(95 \% \mathrm{Cl})\end{array}$ \\
\hline Gender (Female) & $0.52(0.19-1.43)$ & $0.62(0.36-1.10)$ & $1.18(0.63-2.23)$ & $1.37(0.77-2.45)$ & $1.85(0.77-4.42)$ \\
\hline P-value & 0.208 & 0.097 & 0.608 & 0.289 & 0.167 \\
\hline Age $\geq 35$ years & $1.52(0.56-4.12)$ & $1.23(0.78-2.14)$ & $2.30(1.29-4.10)$ & $1.38(0.83-2.30)$ & $2.57(1.23-5.35)$ \\
\hline P-value & 0.414 & 0.329 & 0.005 & 0.217 & 0.012 \\
\hline $\mathrm{BMI}>21.2$ & $0.94(0.35-2.53)$ & $1.27(0.76-2.11)$ & $2.21(1.24-3.92)$ & $1.78(1.07-2.98)$ & $1.78(0.88-3.60)$ \\
\hline P-value & 0.908 & 0.358 & 0.007 & 0.028 & 0.108 \\
\hline CD4 + cells $<200 / \mathrm{mm}^{3}$ & $3.21(1.18-8.73)$ & $1.59(0.88-2.86)$ & $0.82(0.42-1.62)$ & $0.96(0.52-1.75)$ & $0.57(0.23-1.44)$ \\
\hline P-value & 0.023 & 0.124 & 0.570 & 0.884 & 0.233 \\
\hline HAART Initiated & $1.47(0.54-3.98)$ & $1.96(1.17-3.29)$ & $5.81(3.01-11.2)$ & $2.62(1.55-4.44)$ & $3.89(1.76-8.61)$ \\
\hline P-value & 0.453 & 0.01 & $<0.0001$ & $<0.0001$ & 0.001 \\
\hline HIV duration $\geq 20$ months & $1.12(0.42-2.99)$ & $1.19(0.72-1.98)$ & $1.98(1.11-3.51)$ & $1.37(0.82-2.28)$ & $2.11(1.03-4.35)$ \\
\hline P-value & 0.828 & 0.500 & 0.020 & 0.231 & 0.042 \\
\hline TB infection & $1.19(0.32-4.33)$ & $1.11(0.56-2.23)$ & $0.80(0.36-1.79)$ & $0.68(0.33-1.42)$ & $2.28(1.00-5.18)$ \\
\hline P-value & 0.798 & 0.590 & 0.590 & 0.307 & 0.049 \\
\hline
\end{tabular}

HAART, highly active antiretroviral therapy; Gluc, glucose; UOR, un adjusted odds ratio; $\mathrm{Cl}$, confidence interval; $\mathrm{BMI}$, body mass index; TC, total cholesterol; HDL, high-density lipoprotein cholesterol; LDL, low-density lipoprotein cholesterol; TG, triglyceride; p, significance level; TB, tuberculosis.

adults in Ethiopia include PIs as second line regimens [18], only first line regimens, NRTI and NNRTI, were taken by the study participants at Burayu Health Center. Two nucleoside backbones (from AZT/D4T/3TC/TDF) with either NVP or EFV NNRTIs combinations were used. AZT-3TC-NVP combination was the most frequently used drug in study participants, 36 (28.6\%).

In addition to its benefit antiretroviral drugs have been associated with an abnormal fat redistribution syndrome that might raise cholesterol and triglycerides levels, as well as cause insulin resistance $[4,5]$. In line with this, our study showed significant increase of serum lipid levels in

Table 5 Association between cholesterol and HAART initiation, adjusted for the potential confounding factors of study participants at Burayu Health Center, Addis Ababa, Ethiopia, 2012

\begin{tabular}{|c|c|c|c|}
\hline \multirow[t]{3}{*}{ Variables } & \multicolumn{3}{|c|}{ Lipid profile levels } \\
\hline & $\mathrm{TC} \geq 200 \mathrm{mg} / \mathrm{dl}$ & $\mathrm{HDL}<40 \mathrm{mg} / \mathrm{dl}$ & $\mathrm{LDL} \geq 130 \mathrm{mg} / \mathrm{dl}$ \\
\hline & AOR $(95 \% \mathrm{Cl})$ & AOR $(95 \% \mathrm{Cl})$ & AOR $(95 \% \mathrm{Cl})$ \\
\hline Non-HAART** & 1.00 & 1.00 & 1.00 \\
\hline HAART Initiated & $5.46(2.81-10.61)$ & $2.62(1.55-4.44)$ & $3.89(1.76-8.61)$ \\
\hline P-value & $<0.0001$ & $<0.0001$ & 0.001 \\
\hline $\mathrm{BMI} \leq 21.2^{*}$ & 1.00 & 1.00 & 1.00 \\
\hline $\mathrm{BMI}>21.2$ & \multicolumn{3}{|l|}{$1.90(1.03-3.50)$} \\
\hline P-value & \multicolumn{3}{|l|}{0.039} \\
\hline
\end{tabular}

HAART, highly active antiretroviral therapy; $\mathrm{AOR}$, adjusted odds ratio; $\mathrm{Cl}$, confidence interval; BMI, body mass index; TC, total cholesterol; HDL, high-density lipoprotein cholesterol; LDL, low-density lipoprotein cholesterol;

p, significance level; *Reference category.
HAART group than non-HAART group. There was no significant difference of serum lipid profile and glucose levels among different nucleoside combinations of HAART. In contrast, a study from India [10] and Canada [12] showed a significant association of lipoatrophy with D4T use. Especially in Canada, an incident lipoatrophy was associated with duration of D4T [12]. Unlike to these, studies form Spain and France showed the absence of difference in lipid profiles between D4T and AZT treated patients $[19,20]$.

Compared to each other, the independent effect of the use of NVP and EFV based combinations on serum lipid profile level was not seen among our study participants. On the contrary, a 48 week follow up study in Australia found that, the increase of HDL-C was significantly larger for patients receiving NVP than for patients receiving EFV, while the increase in TC was lower. The increase of non-HDL-C was smaller for patients receiving NVP than for patients receiving EFV, as were the increases of TG and LDL-C [21]. In addition, a study in India found that TC level $>200 \mathrm{mg} / \mathrm{dl}$ was more common among patients who received EFV than among those who received NVP [11]. Moreover, a study in USA and Europe found that EFV was associated with higher levels of TC and TG than was NVP [22].

\section{Limitations of the study}

This is a cross-sectional study with no follow up of patients to see the effects of HAART at individual level. In addition, this paper does not include all potential confounders of hyperglycemia and dyslipidemia such as physical exercise. 


\section{Conclusion}

First-line HAART with regimens NRTIs and NNRTIs were associated with potentially atherogenic lipid profile levels compared to untreated HIV infected patients in Ethiopian setting. There were an increased prevalence of hyperglycemia, hypertriglyceridemia and hypercholesterolemia in HAART initiated patients than non-antiretroviral HIV infected patients at Burayu Health Center. This might lead to metabolic complications particularly diabetes mellitus and dyslipidemia which potentially increase risk of cardiovascular diseases. From these findings, serum fasting glucose and lipid profile levels needs to be monitored regularly in HIV infected patients on or without antiretroviral therapy to rule out unwanted effects that can be optimally managed. In addition, further studies on wellcontrolled cohort conditions for the evaluation of longterm effects of HAART treatment on serum glucose and lipid profile level are recommended.

\section{Abbreviations}

3TC: Lamivudine; AIDS: Acquired immunodeficiency syndrome; ART: Antiretroviral therapy; AZT: Zidovudine; D4T: Stavudine; EFV: Efavirenz; HAART: Highly active antiretroviral therapy; HDL-C: High density lipoproteincholesterol; HIV: Human immunodeficiency virus; LDL-C: Low density lipoprotein-cholesterol; NNRTIs: Non-nucleoside reverse transcriptase inhibitors; NRTI: Nucleoside reverse transcriptase inhibitors; NVP: Nevirapine; PIs: Protease inhibitors; SPSS: Statistical package for social sciences; TC: Total cholesterol; TG: Triglycerides.

\section{Competing interests}

Financial competing interests: All authors have no financial relationships relevant to this article to disclose.

Non-financial competing interests: The authors have no non-financial competing interests relevant to this article to disclose.

\section{Authors' contributions}

$M A$, designed the study, performed analysis and interpretation of data including manuscript drafting, SK, BT and GB assisted in the design, interpretation of data and the critical appraisal of the manuscript and AG, FC, TG and PN performed the laboratory activity with MA. All authors read and agreed the final manuscript.

\section{Acknowledgements}

We would like to acknowledge the laboratory technologists of Burayu Health Center and VCT staffs for their support during data collection. Our appreciation is also extended to the Addis Ababa University for financial support, EHNRI for materials and reagents support; and the HIV/AIDS patients for their voluntarily participation in the study.

\section{Author details}

'Department of Clinical Chemistry, School of Biomedical and Laboratory Sciences, College of Medicine and Health Sciences, University of Gondar, Gondar, Ethiopia. ${ }^{2}$ Department of Medical Laboratory Sciences, School of Allied Health Sciences, College of Health Sciences, Addis Ababa University, Addis Ababa, Ethiopia. ${ }^{3}$ Ethiopian Health and Nutrition Research Institute, Addis Ababa, Ethiopia.

Received: 25 September 2013 Accepted: 9 June 2014 Published: 21 June 2014

\author{
References \\ 1. Jayasuriya A, Robertson C, Allan P: Twenty-five years of HIV management. \\ $J$ J Soc Med 2007, 100(8):363-366.
}

2. Sabin CA, Phillips AN: Should HIV therapy be started at a CD4 cell count above 350 cells/[mu] I in asymptomatic HIV-1-infected patients? Curr Opin Infect Dis 2009, 22(2):191.

3. Lima VD, Johnston K, Hogg RS, Levy AR, Harrigan PR, Anema A, Montaner JSG: Expanded access to highly active antiretroviral therapy: a potentially powerful strategy to curb the growth of the HIV epidemic. JID 2008, 198(1):59-67.

4. Larson R, Capili B, Eckert-Norton M, Colagreco JP, Joyce K, Anastasi P, DrNP. Disorders of glucose metabolism in the context of human immunodeficiency virus infection. J AANP 2006, 18(3):92-103.

5. Gallagher DM: Current clinical issues impacting the lives of patients living with HIV/AIDS. J Assoc of Nurses in AIDS care 2007, 18(1):S11-S16.

6. Buchacz K, Weidle PJ, Moore D, Were W, Mermin J, Downing R, Kigozi A, Borkowf CB, Ndazima V, Brooks JT: Changes in lipid profile over 24 months among adults on first-line highly active antiretroviral therapy in the home-based AIDS care program in rural Uganda. JAIDS 2008, 47(3):304.

7. NCEP: Third report of the national cholesterol education program (NCEP) expert panel on detection, evaluation, and treatment of high blood cholesterol in adults (Adult Treatment Panel III) final report. Circulation 2002, 106(25):3143-3421.

8. Araújo PSR, Ximenes RAA, Lopes CFC, Duarte JY, Silva MM, Carneiro EM: Antiretroviral treatment for HIV infection/AIDS and the risk of developing hyperglycemia and hyperlipidemia. Revista do Instituto de Medicina Tropical de São Paulo 2007, 49(2):73-78.

9. Luatngoen J: HAART-associated hyperlipidemia and hyperglycemia in HIV patients. Khon Kaen Hosp Med J 2008, 32(4):60-67.

10. Pujari SN, Dravid A, Naik E, Bhagat S, Tash K, Nadler JP, Sinnott JT: Lipodystrophy and dyslipidemia among patients taking first-line, WHOrecommended highly active antiretroviral therapy regimens in western India. JAIDS 2005, 39(2):199-202.

11. Padmapriyadarsini C, Ramesh Kumar S, Terrin N, Narendran G, Menon PA, Ramachandran G, Subramanyan S, Venkatesan P, Wanke C, Swaminathan S: Dyslipidemia among HIV-infected patients with tuberculosis taking once-daily nonnucleoside reverse-transcriptase inhibitor-based antiretroviral therapy in India. Clin Infect Dis 2011, 52(4):540-546

12. Heath KV, Hogg RS, Singer J, Chan KJ, O'Shaughnessy MV, Montaner JSG Antiretroviral treatment patterns and incident HIV-associated morphologic and lipid abnormalities in a population-based cohort. JAIDS 2002, 30(4):440-447.

13. Yone EWP, Betyoumin AF, Kengne AP, Folefack FJK, Ngogang J, Pefura Yone EW, Betyoumin AF, Kengne AP, Kaze Folefack FJ: First-line antiretroviral therapy and dyslipidemia in people living with HIV-1 in Cameroon: a cross-sectional study. AIDS Res Ther 2011, 8:33.

14. Van Leth F, Hall D, Lange J, Reiss P: Plasma lipid concentrations after 1.5 years of exposure to nevirapine or efavirenz together with stavudine and lamivudine. HIV Med 2006, 7(6):347-350.

15. Ngogang Y: Effect of antiretroviral therapy on lipid metabolism in HIV/ AIDS subjects in Cameroon. J Med Sci 2005, 5(2):78-82.

16. Calza L, Manfredi R, Farneti B, Chiodo F: Incidence of hyperlipidaemia in a cohort of 212 HIV-infected patients receiving a protease inhibitor-based antiretroviral therapy. Int J Antimicrob Agents 2003, 22(1):54-59.

17. Young J, Weber R, Rickenbach M, Furrer H, Bernasconi E, Hirschel B, Tarr PE, Vernazza P, Battegay M, Bucher HC: Lipid profiles for antiretroviral-naive patients starting PI-and NNRTI-based therapy in the Swiss HIV Cohort Study. Antivir Ther 2005, 10:585-591.

18. HAPCO/MoH: Guidelines for Management of Opportunistic Infections and Anti-Retroviral Treatment in Adolescents and Adults in Ethiopia. 2008 URL: www.who.int/hiv/pub/guidelines/ethiopia_art.pdf.

19. Domingo P, Sambeat MA, Pérez A, Ordoñez J, Rodríguez J, Vázquez G: Fat distribution and metabolic abnormalities in HIV-infected patients on first combination antiretroviral therapy including stavudine or zidovudine: role of physical activity as a protective factor. Antivir Ther 2003, 8(3):223-232.

20. Saint-Marc T, Partisani M, Poizot-Martin I, Bruno F, Rouviere O, Lang JM, Gastaut JA, Touraine JL: A syndrome of peripheral fat wasting (lipodystrophy) in patients receiving long-term nucleoside analogue therapy. AIDS 1999, 13(13):1659-1667.

21. Van Leth F, Phanuphak P, Stroes E, Gazzard B, Cahn P, Raffi F, Wood R, Bloch M, Katlama C, Kastelein JJP: Nevirapine and efavirenz elicit 
different changes in lipid profiles in antiretroviral-therapy-naive patients infected with HIV-1. PLoS Med 2004, 1(1):e19.

22. Fontas E, Van Leth F, Sabin CA, Friis-Møller N, Rickenbach M, D'Arminio Monforte A, Kirk O, Dupon M, Morfeldt L, Mateu S, Petoumenos K, El-Sadr W, De Wit S, Lundgren JD, Pradier C, Reiss P: Lipid profiles in HIV-infected patients receiving combination antiretroviral therapy: are different antiretroviral drugs associated with different lipid profiles? I Infect Dis 2004, 189(6):1056-1074.

doi:10.1186/1756-0500-7-380

Cite this article as: Abebe et al: Antiretroviral treatment associated

hyperglycemia and dyslipidemia among HIV infected patients at Burayu Health Center, Addis Ababa, Ethiopia: a cross-sectional comparative study. BMC Research Notes 2014 7:380.

\section{Submit your next manuscript to BioMed Central and take full advantage of:}

- Convenient online submission

- Thorough peer review

- No space constraints or color figure charges

- Immediate publication on acceptance

- Inclusion in PubMed, CAS, Scopus and Google Scholar

- Research which is freely available for redistribution 